\title{
How French general practitioners manage and prevent recurrent respiratory tract infections in children: the SOURIRRE survey
}

This article was published in the following Dove Press journal:

International Journal of General Medicine

3 March 2017

Number of times this article has been viewed

\section{Bruno Chicoulaa' \\ Hervé Haas ${ }^{2}$ \\ Jérôme Viala ${ }^{3}$ \\ Maryline Salvetat ${ }^{4}$ \\ Jean-Pierre Olives ${ }^{5}$}

'Faculty of Medicine, Toulouse Rangueil, Toulouse, ${ }^{2}$ Paediatric Emergency and Infectious Disease Departments, Lenval University Hospital, Nice, ${ }^{3}$ Gastroenterology Department, Robert-Debré Hospital, Paris, ${ }^{4}$ Sports and General Medicine Practice, Labruguière, ${ }^{5}$ Gastroenterology and Nutrition Department, Children's Hospital, University Hospital, Toulouse, France

Correspondence: Bruno Chicoulaa Faculté de Médecine de Toulouse Rangueil, 133 route de Narbonne, 31063

Toulouse Cedex, France

$\mathrm{Tel}+33561219878$

Fax +33561133377

Email brunol.chicoulaal@dumg-

toulouse.fr
Background: Recurrent respiratory tract infections (RRTIs) are the most common reason for children's visits to primary care physicians in France; however, little is known about general practitioners' (GPs) opinions and expectations concerning the management and prevention of these common and recurrent pathologies.

Purpose: To describe French GPs' daily practice in the management of respiratory infections and the prevention of their recurrence in children.

Methods: A sample group of French GPs answered a structured questionnaire on risk factors, RRTI management, antibiotic use and prevention measures.

Results: A total of 358 GPs participated in the survey. Rhinopharyngitis, the most frequent respiratory infection, was considered to be recurrent if six or more episodes occurred in a year. Four risk factors were acknowledged as substantial: living in communities, passive smoking, pollution and allergies. Around $63 \%$ of GPs said that RRTIs are too often treated with antibiotics. More than $85 \%$ thought that prevention of RRTIs is possible. Smoking cessation, vaccination, allergen avoidance and hygiene were identified as the main preventive measures. A large majority of GPs (84\%) prescribed products for prevention and $\sim 90 \%$ would prescribe a product stimulating immunity if the efficacy and tolerability of these agents was proven and confirmed in their daily practice.

Conclusions: French GPs are well aware of the health and socioeconomic burdens resulting from RRTIs, as well as the risk of antibiotic overuse. They have a prevention-oriented approach, implement preventive measures when possible and prescribe products for prevention.

Keywords: disease management, epidemiology, general practice, immunity, therapeutics

\section{Introduction}

Respiratory tract infections (RTIs) are common in children. ${ }^{1}$ Several factors are responsible for this high prevalence: anatomical conditions; the immaturity of children's immune systems; the high prevalence of atopy; the significant number of airborne viruses ( $>200)$, the highly contagious nature of these viruses, which is exacerbated by day care attendance; as well as exposure to toxic agents, such as passive smoking and pollution. ${ }^{2,3}$

These illnesses include the upper RTIs (URTIs; rhinopharyngitis, sinusitis, tonsillitis, otitis) and the lower RTIs (bronchiolitis, bronchitis and pneumonitis). RTIs are mostly of viral origin and relatively benign, but due to their recurrence they have a significant impact on family life and represent a considerable socioeconomic burden. ${ }^{4}$ The treatment of acute episodes is thoroughly described in clinical guidelines. ${ }^{3,5,6}$ 
However, preventive measures, which are aimed at reducing the frequency of RTIs and therefore the consumption of medical resources, are less frequently considered.

RTIs are the most common reason for children to visit general practitioners (GPs), ${ }^{1}$ but little is known regarding GPs' attitudes, daily practices and expectations concerning the prevention and management of RTIs. To answer this question, the Spécificités, OccUrrence et pRévention des Infections Respiratoires REcidivantes (SOURIRRE) survey on the specifics, occurrence and prevention of recurrent respiratory tract infections (RRTIs) in children in France was performed. The aim of this survey was to describe French GPs' practices regarding the prevention and management of RTIs in children.

\section{Methods}

\section{Study design}

The SOURIRRE study was a noninterventional, epidemiological, descriptive survey designed to assess GPs' practices with respect to RTIs. A sample group of private GPs covering all French regions were invited by email to participate. Those who accepted were included and received compensation for the time they spent responding to the survey questions. The structured questionnaire, validated by an expert committee of pediatricians and GPs, required $\sim 10$ minutes to complete and was available online from 1 to 14 September 2015.

The survey only collected declarative answers from GPs regarding their practices, and no data concerning their patients. Consent from participants was implied by completion and submission of the online survey. Specific ethical approval for this study was not required by the authors' local university ethics committee. The survey was declared to the French National Medical Council (CNOM) and a research authorization from the French independent administrative authority protecting privacy and personal data (CNIL; "National Commission for Computing and Liberties") was obtained.

\section{Measured parameters}

The questionnaire included 14 questions on demographics, the GP's practice (rural or urban, in groups or alone), patients, RTI awareness, risk factors, management of RRTIs, antibiotic use, preventive measures and their usual prescriptions for prevention.

\section{Statistics}

Data entry was performed online through an electronic Case Report Form (CSOnline) with integrated verification of coherence. The analysis was performed with SAS Version
9.4. Quantitative variables were described by the number of informed values, number of missing data, average, standard deviation, median, first and third quartiles, minimums and maximums. Qualitative variables were described by the number of informed values, number of missing values, frequency and percentage by modality. No missing data were replaced.

\section{Results \\ Demographics}

Of the 8,000 GPs contacted, 358 participated in the survey. The mean age was $54.81 \pm 8.29$ years. Around half of them $(52.5 \%)$ worked alone. RRTIs were a frequent reason for patient visits. Each month, $>65 \%$ of the GPs saw at least five children $<3$ years, and $>70 \%$ saw at least five children aged $\geq 3$ years, presenting for RRTIs (Table 1).

\section{RRTI frequency}

Rhinopharyngitis and otitis were the most frequent infections, followed by bronchiolitis and bronchitis in younger children, and tonsillitis and bronchitis in children $>3$ years. On average, GPs considered RTIs as recurrent when the minimum number of episodes was $5.90 \pm 3.25$ for

Table I Demographic characteristics of the 358 study participants

\begin{tabular}{|c|c|}
\hline Characteristics & GPs, n (\%) \\
\hline Female & $93(26)$ \\
\hline Male & $265(74)$ \\
\hline \multicolumn{2}{|l|}{ Practice type } \\
\hline In rural areas & $120(33.5)$ \\
\hline In cities $<50,000$ inhabitants & $117(32.7)$ \\
\hline In cities $>50,000$ inhabitants & $121(33.8)$ \\
\hline In a group & $170(47.5)$ \\
\hline Alone & $188(52.5)$ \\
\hline \multicolumn{2}{|c|}{ Number of children $<3$ years seen during the autumn-winter period } \\
\hline$<20$ & $61(17)$ \\
\hline $20-50$ & $191(53.4)$ \\
\hline$>50$ & $106(29.6)$ \\
\hline \multicolumn{2}{|c|}{$\begin{array}{l}\text { Number of children }<3 \text { years with RRTIs seen during the autumn-winte } \\
\text { period }\end{array}$} \\
\hline$<5$ & $118(33)$ \\
\hline $5-15$ & $199(55.6)$ \\
\hline$>15$ & $41(11.5)$ \\
\hline \multicolumn{2}{|c|}{ Number of children $\geq 3$ years seen during the autumn-winter period } \\
\hline$<20$ & $16(4.5)$ \\
\hline $20-50$ & $163(45.5)$ \\
\hline$>50$ & $179(50)$ \\
\hline \multicolumn{2}{|c|}{$\begin{array}{l}\text { Number of children } \geq 3 \text { years with RRTIs seen during the autumn-winte } \\
\text { period }\end{array}$} \\
\hline$<5$ & $94(26.3)$ \\
\hline $5-15$ & $198(55.3)$ \\
\hline$>15$ & $66(18.4)$ \\
\hline
\end{tabular}

Abbreviations: GPs, general practitioners; RRTls, recurrent respiratory tract infections. 
rhinopharyngitis, $4.25 \pm 2.31$ for tonsillitis, 3.95 \pm 1.90 for otitis and 3.79 \pm 1.96 for bronchitis (Figure 1). Most GPs (73.7\%) verified the number of RTI recurrences each year systematically.

\section{Risk factors}

Four risk factors were considered as preponderant by the physicians: living in communities, passive smoking, pollution and atopy (Figure 2). Other factors, such as immune deficiency, living in hot, cold or humid atmospheres, urban life, prematurity or cesarean birth, gastroesophageal reflux, not being vaccinated against Haemophilus influenzae or pneumococcal disease, sibling relationships or the presence of animals at home were less frequently quoted as potential risk factors.

\section{RRTI management}

GPs requested additional investigations in around four patients out of ten, especially when the infection had a negative impact on daily life $(56.1 \%)$ or for a differential diagnosis $(40.3 \%)$. On occasion, these investigations were motivated by the patient's history $(23.3 \%)$ or performed at the parents' request (21.2\%). Biological checks (complete blood count, ferritin dosage and C-reactive protein concentrations),

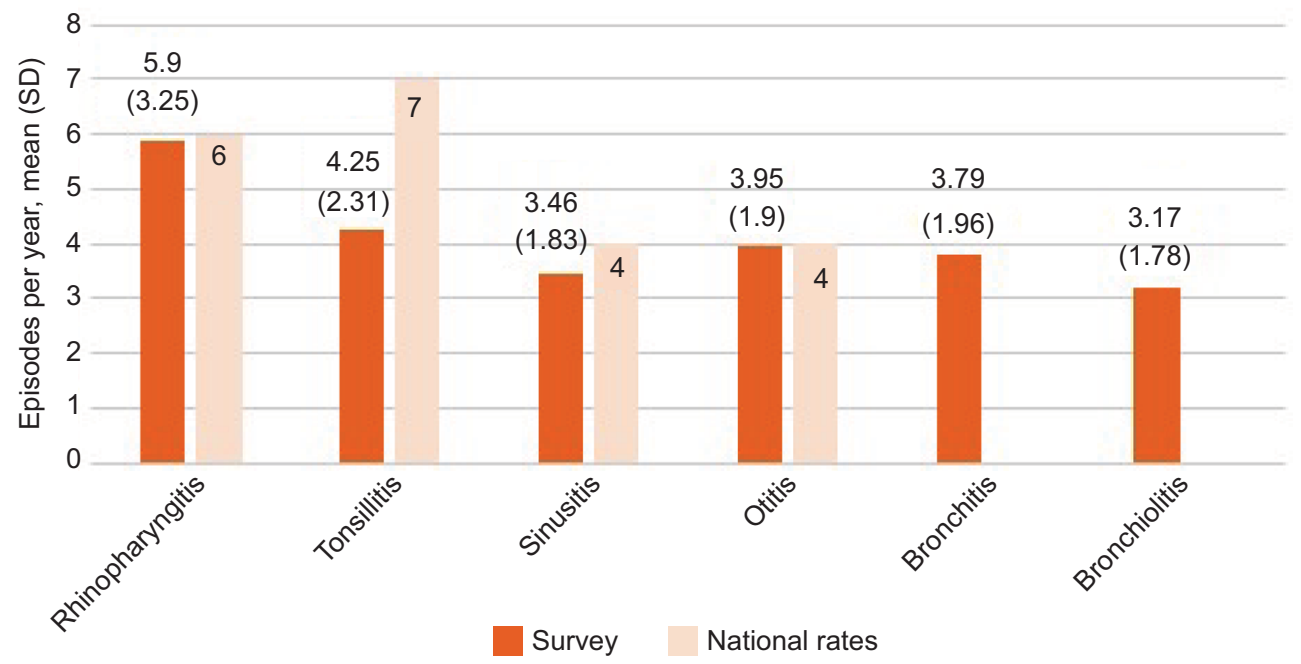

Figure I Minimum number of episodes per year for general practitioners to consider the illness as recurrent and number for definition of recurrence found in the literature (national rates in France). ${ }^{7}$

Note: Data shown as mean (standard deviation).

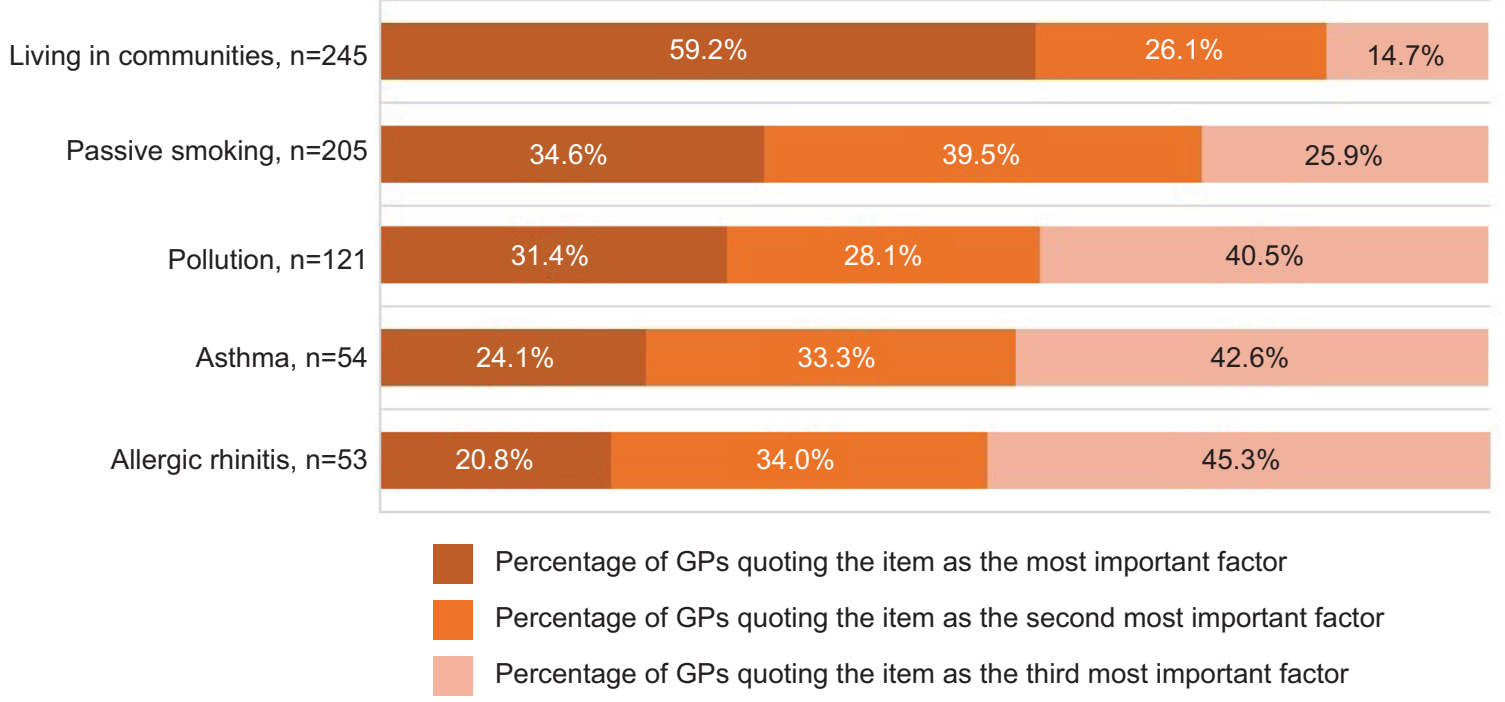

Figure 2 Main risk factors for recurrent respiratory tract infections.

Abbreviation: GPs, general practitioners. 
specialist referral or medical imaging were the most frequent assessments requested.

GPs acknowledged antibiotic use in $20 \%$ of rhinopharyngitis cases, $35.1 \%$ of tonsillitis cases (when a rapid Streptococcus test was not performed), $49.1 \%$ of bronchitis cases and $61.3 \%$ of sinusitis cases.

Around $63 \%$ of GPs agreed with the proposition that RTIs are treated with antibiotics too often, and that it would be better to prevent their recurrence. In descending order of frequency, other GPs believed that RTIs may lead to complications and hence everything should be done to limit them $(27.1 \%)$; that they are necessary for the maturation of the immune system and it is not necessary to prevent them $(8.7 \%)$; or that they do have health consequences, but there is no means of preventing them (1.7\%; Table 2$)$.

More than $40 \%$ of physicians said that for half of their cases, they had to write a sick certificate for the child's day

Table 2 GPs' opinions regarding RRTIs

\begin{tabular}{lc}
\hline With respect to RRTIs, which do you consider the & GPs (\%) \\
more accurate sentence? (select only one answer) & \\
\hline These infections are treated with antibiotics too often and & 62.6 \\
it would be better to prevent them & \\
These infections might lead to complications and everything & 27.1 \\
should be done to limit them & \\
These infections are part of the maturation of the immune & 8.7 \\
system and it is not necessary to prevent them & 1.7 \\
These infections do have health consequences but I have & \\
no means to prevent them &
\end{tabular}

Abbreviations: GPs, general practitioners; RRTls, recurrent respiratory tract infections. care center, while $30 \%$ reported providing a certificate for the parent's employer, and $6 \%$ provided a sick leave certificate for the parent.

\section{Preventive measures}

More than $85 \%$ of GPs believe it is possible to prevent RRTIs. Cessation of smoking, vaccination against $H$. influenza and Streptococcus pneumoniae, allergen avoidance and hygiene (hand washing) were quoted as the most important preventive measures to implement. About 35\% used surgery (tonsillectomy or adenoidectomy) as a preventive measure. Conversely, $15 \%$ thought that prevention is not possible for various reasons, including the necessity for immune system maturation; because it is not possible to prevent RRTIs or no effective preventive product is available.

\section{Prescriptions for preventive products}

Overall, 84\% of GPs prescribed products for the prevention of RRTIs; mostly trace elements, pre/probiotics, homeopathy and vitamins (Figure 3 ). Only $16 \%$ of GPs did not prescribe a product for RRTI prevention, primarily as a result of the lack of evidence for such products. Around nine out of ten GPs $(87.7 \%)$ would prescribe a product stimulating immunity, mostly for rhinopharyngitis, if such a product was proven to be effective, was well tolerated for RRTI prevention and showed confirmed efficacy in their daily practice. The best time for starting an immunostimulant was considered to be when the child returned to school or day care by $45.9 \%$ of GPs, or in summer by $36.3 \%$.

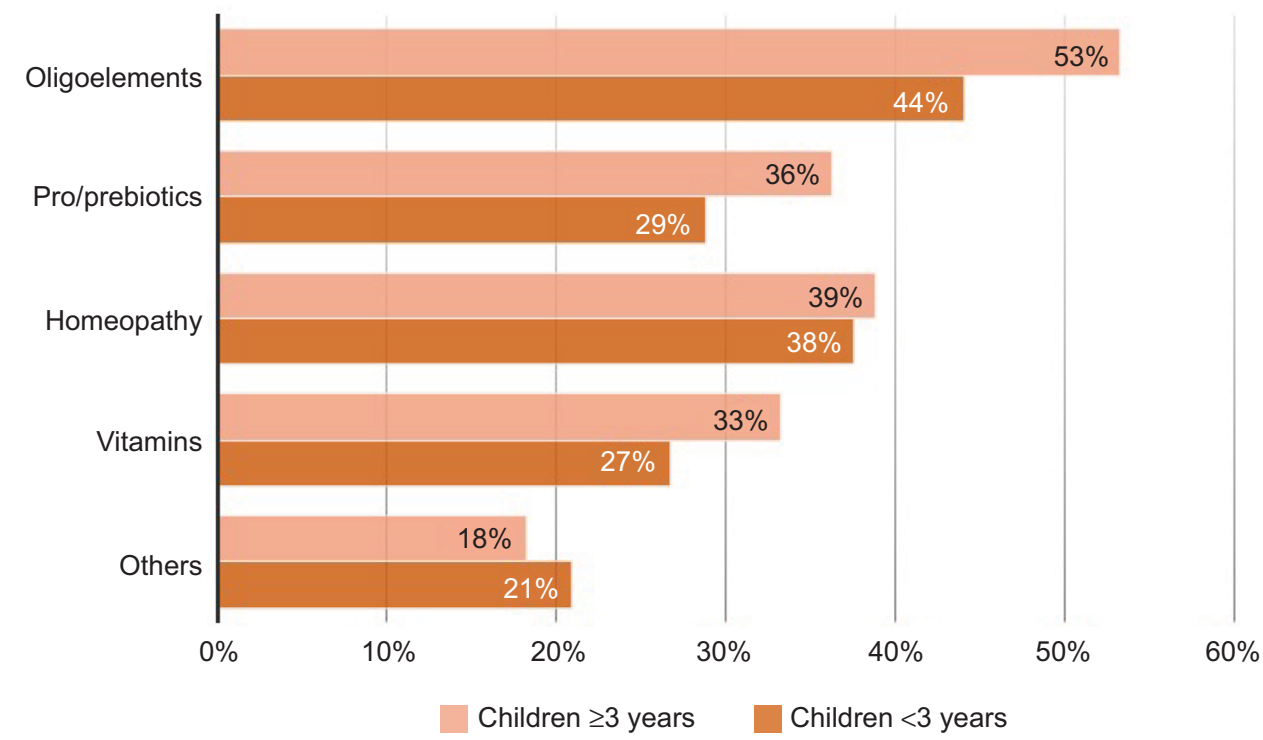

Figure 3 Prescriptions for products for the prevention of recurrent respiratory tract infections; percentage of general practitioners prescribing the class of product. 


\section{Discussion}

\section{GPs play a key role in the management of RRTIs}

In France, $40 \%$ of children under the age of 3 years are followed by GPs, $55 \%$ by both GPs and pediatricians and $5 \%$ are followed by pediatricians only. ${ }^{1}$ Rhinopharyngitis is the first diagnosis reported in general practice, representing $18.6 \%$ of all consultations for patients $<16$ years of age. ${ }^{1}$ The survey confirmed that RTIs are a daily concern for GPs, who considered these infections as recurrent when at least six episodes of rhinopharyngitis occurred per year, or four episodes for otitis, 3.5 for sinusitis and four for tonsillitis. This is very close to the definition of recurrence found in the literature (six episodes for rhinopharyngitis, four episodes for otitis and four episodes for sinusitis). ${ }^{7}$ However, French GPs considered tonsillitis to be recurrent at four or more episodes per year, instead of the seven episodes per year cited in the literature.

\section{Importance of health and socioeconomic consequences of RRTls}

In terms of their health consequences, $27 \%$ of GPs agreed that these infections may lead to complications (Table 2). Superinfections of viral diseases, such as otitis, may have long-term consequences for the child's health ${ }^{8}$ and may even be life-threatening (e.g., septicaemia, meningitis). Fortunately, RRTIs appear to be a transitory problem during the early years of life. In a large prospective population-based group of Dutch children followed from the age of 2 to 21 years of age, $23 \%$ of participants suffered from recurrent URTIs, but only $1 \%$ had persistent RRTIs (defined as present from 2 to 21 years of age). ${ }^{9}$

RTIs are a common reason for school or work absenteeism. GPs were frequently asked to write a sick certificate for the child's day care center or school, and on occasion, to sign a sick leave certificate for one of the parents. Family life is frequently impacted, not only due to the usual sleep disturbance and problems associated with caring for a sick child, but also as a result of parental infection, which can cause work absenteeism. A Canadian study reported that transmission of acute RTIs to parents occurred about once in every three episodes, leading to sick leave for $34 \%$ of parents. ${ }^{10}$

It has been estimated that there are over 18 million consultations for ear, nose and throat (ENT) infections each winter in France, with rhinopharyngitis representing the large majority of these, at 11.9 million consultations. Moreover, the direct costs of ENT infections have been estimated to be over a billion euros per year. ${ }^{3}$ In addition, the family budget can be impacted by these illnesses, as some costs are borne by the parents (over-the-counter medications and/or nonreimbursed products).

\section{RTI management and antibiotic overuse}

GPs acknowledged prescribing antibiotics for $20 \%$ of cases of rhinopharyngitis, $35.1 \%$ of cases of tonsillitis (when the rapid test is not available), $49.1 \%$ of cases of bronchitis and $61.3 \%$ of cases of sinusitis. French recommendations on the treatment of URTIs are clear. ${ }^{3}$ Notably, antibiotics are not recommended for rhinopharyngitis or bronchitis, except in the case of bacterial superinfection. For tonsillitis, French authorities recommend the use of rapid antigen tests in children $>3$ years of age to confirm the presence of Group A Streptococcus. If the test is positive, antibiotics are recommended to prevent poststreptococcal complications. The devices are free of charge and at GPs' disposal. A recent survey in the center of France showed that $66 \%$ of physicians used the test, but despite this, $28 \%$ acknowledged that they prescribed antibiotics even in the case of a negative test result. ${ }^{11}$ Recently, French investigators have developed arguments against the use of antibiotics in cases of a positive rapid test result. They concluded that overtreatment of streptococcal pharyngitis leads to inappropriate antibiotic use. ${ }^{12}$

Similar to other countries, France has implemented measures to limit the prescription of antibiotics. The first French Antibiotic Plan 2001-2005 was successful in decreasing antibiotic consumption; however, since 2010 the tendency for antibiotic use has been increasing. Despite national recommendations and successive antibiotic plans, prescription of antibiotics remains 30\% higher than the European average, representing an extra cost of 71 million euros. In 2014, 5,662 notifications of adverse effects linked to antibiotics were made to French health authorities. Around 158,000 people were affected by a multiresistant bacterial infection and 12,500 died as a result. ${ }^{13}$ French GPs are well aware that inappropriate antibiotic use generates antibiotic resistance and two thirds of GPs agreed that RRTIs are too often treated with antibiotics.

France is not the only country overusing antibiotics. In the Netherlands, $30 \%$ of children presenting with URTIs received antibiotics for their symptoms. ${ }^{9}$ A study of medicine used in children in Germany recently reported that $13.8 \%$ of participants had used drugs to treat a common cold or an URTI in the previous 7 days; half of them took prescribed medications, of which antibiotics represented $11.5 \% .{ }^{14}$ The reasons for antibiotic over-prescription are numerous. ${ }^{15,16}$ One of them is the difficulty in identifying children at risk of poor 
outcomes. Another frequent justification is perceived parental expectations that antibiotics are necessary. However, it seems that there is poor agreement between parental expectations and clinicians' perceptions of these expectations. ${ }^{17}$

\section{Risk factors and associated prevention measures}

Living in communities was the first risk factor quoted by GPs. In a Dutch sample, children attending day care during the first year of life had more GP-diagnosed URTIs and acute otitis media episodes before the age of 1 year (but fewer beyond the age of 4 years) in comparison with children staying at home. This association between day care attendance and infections beyond preschool age showed a protective effect of day care against RTIs in later childhood. ${ }^{18}$

Passive smoking was the second most important risk factor reported by GPs, and smoking cessation was considered an important preventive measure. However, GPs were frequently discouraged by patients' attitudes toward their advice regarding smoking cessation, even though the serious consequences of exposure to second-hand smoke are well known. ${ }^{19,20}$

GPs considered pollution to be the third major risk factor for RRTIs. Unfortunately, an individual's level of exposure to pollution, and the impact of this exposure, is difficult to assess and little can be done at a medical level with respect to this increasingly important risk factor. ${ }^{21}$

Atopy, allergic rhinitis and asthma were topics of concern for GPs, who offered the following preventive measures: allergen avoidance, allergy assessment and referral to an allergist. Measures to avoid the development of atopy are still under discussion. Recent data in the medical literature suggests a possible role for bacteria; some bacteria are pathogenic colonizers of the microbiome without causing infection, and these species were found to be associated with the severity of asthma. Conversely, some commensal bacteria are thought to confer protection against allergic diseases. ${ }^{22}$

Thirty-five per cent of GPs reported using surgery (tonsillectomy or adenoidectomy), as a preventive measure for URTIs; they referred the patient to an ENT specialist who recommended or not surgery. In a Dutch sample of children with recurrent URTIs, $32 \%$ underwent an ENT operation. ${ }^{9} \mathrm{~A}$ recent paper on the evolution of adenoidectomy and tonsillectomy rates in the UK reported that the rate in the global population of children aged 4-15 years has decreased from $3.5 / 1,000$ children in 2001-2002 to $3.0 / 1,000$ children in 2011-2012. However, during this period, adenoidectomy and tonsillectomy rates among children aged $<4$ years increased from 1.35 to $2.13 / 1,000$ children, largely driven by the increasing frequency of obstructive sleep apnea syndrome. ${ }^{23}$

Vaccines that are effective against RTIs are scarce (influenza, diphtheria, $H$. influenzae and pneumococcal disease) in comparison with the number of pathogens. There are currently no vaccines available against respiratory syncytial virus, human parainfluenza virus, adenovirus or rhinovirus. Despite this, $81 \%$ of GPs present vaccination as an important preventive measure against RRTIs. Some GPs have negative attitudes toward vaccination, in general, or certain vaccines in particular. Notably, questions have been raised about the safety and benefits of the vaccines against hepatitis B and H1N1 influenza after the national campaigns promoting them. Approximately 16\% of French GPs are hesitant about the use of vaccines, and $43 \%$ will sometimes or never recommend at least one specific vaccine to their patients. ${ }^{24}$ Very recently French health authorities proposed opening a debate in an effort to educate people about the benefits of vaccination.

\section{Frequent prescription of products for prevention}

Overall, $84 \%$ of GPs acknowledged that they prescribed products for the prevention of RRTIs; mostly trace elements (iron, zinc and sulfur), pre/probiotics, homeopathic remedies or vitamins. Iron deficiency assessment with ferritin levels is frequently requested by GPs and iron supplementation is a conventional measure.

While there is evidence that homeopathy has little or no effect on URTIs or flu-like symptoms, its potential for reducing antibiotic consumption has been proposed..$^{25,26}$ The EPI3 survey in France showed that patients who consult GPs certified in homeopathy used fewer antibiotics and antipyretic/ anti-inflammatory products. ${ }^{25}$ These results emphasize the importance of the physicians' attitude toward viral infections.

With regard to oral probiotics, a recent review evaluated the efficacy of probiotics in pediatric RTIs, and concluded that a better understanding was required for the effects of different probiotic strains to evaluate their effect on the frequency and severity of RTIs in children. ${ }^{27}$

Different types of vitamins and various complementary products are widely available in France. They are usually considered as harmless, if not useful. Overall, these results indicate that physicians routinely prescribe products that are supported by relatively low levels of evidence.

More than $90 \%$ of GPs said that they would prescribe a product stimulating or modulating immunity if its efficacy 
and tolerability had been proven and if its efficacy had been confirmed in their daily practice. Recently, a new kind of immunomodulatory product (beta-glucan) that has been marketed in several European countries has shown clinical efficacy. ${ }^{28}$ It will be interesting to confirm its efficacy and tolerability in clinical practice.

\section{Strengths and limitations of the study}

The answers collected in the survey were on a declarative basis. In terms of the representativeness of the sample, 8,000 physicians corresponding to a representative sample of the 56,000 French private GPs covering all French regions were invited by email to participate in the survey which was stopped when the number needed to identify a difference between regions was reached. More male doctors participated in the survey $(74 \%)$ in comparison with the national ratio of male to female GPs (64\%); however, the mean age (54.8 \pm 8.3 years) was similar to the mean age of the national GP population (53 years). ${ }^{29}$

To our knowledge, the SOURIRRE survey is the first to report French GPs' daily practices for the prevention of RRTIs. Despite the relatively small number of respondents, our findings are in line with the previously published literature. The strong expectations of GPs concerning the prevention of RRTIs highlight the need for new or improved preventive measures.

\section{Conclusion}

The SOURIRRE survey has revealed three interesting points concerning the management of RRTIs in France. First, antibiotics are overused in the treatment of URTIs. Second, French GPs are strongly in favor of promoting a range of preventive measures that can be taken against RTIs. Finally, French GPs have an expectation that new medical products with proven efficacy and tolerability, particularly in children, will be developed.

\section{Acknowledgment}

The authors express their gratitude to all the GPs who took part in the study.

\section{Disclosure}

Bruno Chicoulaa, Hervé Haas, Jérôme Viala, and Jean-Pierre Olives received honoraria from Pierre Fabre Health Care for their participation in symposia and/or consulting fees for the survey. Maryline Salvetat is a consultant for Pierre Fabre Health Care. The authors report no other conflicts of interest in this work.

\section{References}

1. Franc C, Le Vaillant M, Rosman S, Pelletier-Fleury N. The Care of Children in General Practice: Types of Consultations and Visits 2007 [La prise en charge des enfants en médecine générale: une typologie des consultations et visites 2007]. Available from: http:// www.drees.sante.gouv.fr/IMG/pdf/er588.pdf. Accessed October 25, 2016. French.

2. West JV. Acute upper airway infections. Br Med Bull. 2002;61: 215-230.

3. Cohen R, Azria R, Barry B, et al. Good Practice Recommendations: Current Practice in Systemic Antibiotic Therapy for Upper Respiratory Tract Infections in Adults and Children 2011 [Recommandations de bonne pratique: Antibiothérapie par voie générale en pratique courante dans les infections respiratoires hautes de l'adulte et l'enfant 2011]. Available from: http://www.infectiologie.com/UserFiles/File/medias/ Recos/2011-infections-respir-hautes-argumentaire.pdf. Accessed October 25, 2016. French.

4. Toubiana L, Clarisse T, N'Guyen TT, Landais P. Hivern@le—KhiObs Observatory: surveillance of acute ear, nose, and throat (ENT) diseases in children during winter in France [Observatoire Hivern@le - KhiObs : surveillance épidémiologique des pathologies hivernales de la sphère ORL chez l'enfant en France]. Avialable from: http://www.invs.sante. fr/beh/2009/01/. Accessed October 25, 2016. French.

5. National Institute for Health and Clinical Excellence: Guidance. Respiratory Tract Infections - Antibiotic Prescribing: Prescribing of Antibiotics for Self-Limiting Respiratory Tract Infections in Adults and Children in Primary Care. London, UK: National Institute for Health and Clinical Excellence (UK); Centre for Clinical Practice at NICE; 2008.

6. CDC pediatric treatment recommendations' document. Available from: http://www.invs.sante.fr/beh/2009/01/. Accessed October 25, 2016.

7. Cohen R, Just J, Koskas M, et al. Recurrent respiratory tract infections: what results, what treatments? [Infections respiratoires récidivantes: quels bilans, quels traitements?] Arch Pédiatr. 2005;2:83-90. French.

8. Cherpillod J. Acute otitis media in children. Int J Gen Med. 2011; 4:421-423.

9. Rovers MM, Balemans WA, Sanders EA, van der Ent CK, Zielhuis GA, Schilder AG. Persistence of upper respiratory tract infections in a cohort followed from childhood to adulthood. Fam Pract. 2006;23(3): 286-290.

10. Sacri AS, De Serres G, Quach C, Valiquette L, Skowronski DM. Transmission of acute gastroenteritis and respiratory illness from children to parents. Pediatr Infect Dis J. 2014;33(6):583-588.

11. Saunier A. Use of the Rapid Diagnostic test for Tonsillitis in General Practice: Analysis of the Practices of General Practitioners in Haute Vienne [Utilisation du test de diagnostic rapide des angines en médecine générale: analyse des pratiques des médecins généralistes installés en Haute Vienne]. Available from: http://www.voixmedicales.fr/wpcontent/uploads/2013/12/Th\%C3\%A8se-Alexandre-Saunier-VF.pdf. Accessed October 25, 2016. French.

12. Edouard S, Michel-Lepage A, Raoult D. Does it make sense to detect Streptococcus pyogenes during tonsillitis in Europe to prevent acute rheumatic fever? Clin Microbiol Infect. 2014;20(12):O981-O982.

13. Institut de Veille Sanitaire. Consumption of antibiotics and resistance to antibiotics in France: the need for a determined and continuing mobilisation. Report on the surveillance results, 17 November 2015 [Consommation d'antibiotiques et résistance aux antibiotiques en France: nécessité d'une mobilisation déterminée et durable. Bilan des données de surveillance, 17 Novembre 2015]. Available from: www.invs. sante.fr/Publications-et-outils/Rapports-et-syntheses/Maladies-infectie uses/2015/Consommation-d-antibiotiques-et-resistance-aux-antibiotiques-en-France-necessite-d-une-mobilisation-determinee-et-durable. Accessed October 25, 2016. French.

14. Eckel N, Sarganas G, Wolf IK, Knopf H. Pharmacoepidemiology of common colds and upper respiratory tract infections in children and adolescents in Germany. BMC Pharmacol Toxicol. 2014;15:44. 
15. Yardley L, Douglas E, Anthierens S, et al. Evaluation of a web-based intervention to reduce antibiotic prescribing for LRTI in six European countries: quantitative process analysis of the GRACE/INTRO randomised controlled trial. Implement Sci. 2013;8:134

16. Anthierens S, Tonkin-Crine S, Cals JW, et al. Clinicians'views and experiences of interventions to enhance the quality of antibiotic prescribing for acute respiratory tract infections. J Gen Intern Med. 2015;30(4): $408-416$.

17. Turnbull SL, Redmond NM, Lucas P, et al. The CHICO (Children's Cough) Trial protocol: a feasibility randomised controlled trial investigating the clinical and cost-effectiveness of a complex intervention to improve the management of children presenting to primary care with acute respiratory tract infection. BMJ Open. 2015;5(9):e008615.

18. de Hoog ML, Venekamp RP, van der Ent CK, et al. Impact of early daycare on healthcare resource use related to upper respiratory tract infections during childhood: prospective WHISTLER cohort study. BMC Med. 2014;12:107.

19. Goldstein AO. Is exposure to secondhand smoke child abuse? Yes. Ann Fam Med. 2015;13(2):103-104.

20. Walker N, Johnston V, Glover M, et al. Effect of a family-centered, secondhand smoke intervention to reduce respiratory illness in indigenous infants in Australia and New Zealand: a randomized controlled trial. Nicotine Tob Res. 2015;17(1):48-57

21. Darrow LA, Klein M, Flanders WD, Mulholland JA, Tolbert PE, Strickland MJ. Air pollution and acute respiratory infections among children 0-4 years of age: an 18-year time-series study. Am J Epidemiol. 2014;180(10):968-977.

22. Liu AH. Revisiting the hygiene hypothesis for allergy and asthma. J Allergy Clin Immunol. 2015;136(4):860-865.
23. Koshy E, Bottle A, Murray J, Sharland M, Saxena S. Changing indications and socio-demographic determinants of (adeno)tonsillectomy among children in England - are they linked? A retrospective analysis of hospital data. PloS One. 2014;9(8):e103600.

24. Verger P, Fressard L, Collange F, et al. Vaccine hesitancy among general practitioners and its determinants during controversies: a national cross-sectional survey in France. EBioMedicine. 2015;2(8):889-895.

25. Grimaldi-Bensouda L, Begaud B, Rossignol M, et al. Management of upper respiratory tract infections by different medical practices, including homeopathy, and consumption of antibiotics in primary care: the EPI3 cohort study in France 2007-2008. PloS One. 2014;9(3): e89990.

26. Jong MC, Buskin SL, Ilyenko L, et al. Effectiveness, safety and tolerability of a complex homeopathic medicinal product in the prevention of recurrent acute upper respiratory tract infections in children: a multicenter, open, comparative, randomized, controlled clinical trial. Multidiscip Respir Med. 2016;11:19.

27. Esposito S, Rigante D, Principi N. Do children's upper respiratory tract infections benefit from probiotics? BMC Infect Dis. 2014;14:194.

28. Jesenak M, Majtan J, Rennerova Z, Kyselovic J, Banovcin P, Hrubisko M. Immunomodulatory effect of pleuran (beta-glucan from Pleurotus ostreatus) in children with recurrent respiratory tract infections. Int Immunopharmacol. 2013;15(2):395-399.

29. Conseil National de l'ordre des Médecins. Atlas of Medical Demographics in France. the Situation at 1 January 2015 [Atlas de la démographie médicale en France. Situation au 1er janvier 2015]. Available from: https:/www.conseil-national.medecin.fr/sites/default/ files/atlas_national_de_la_demographie_medicale_2015.pdf. Accessed October 25, 2016. French.
International Journal of General Medicine

\section{Publish your work in this journal}

The International Journal of General Medicine is an international, peer-reviewed open-access journal that focuses on general and internal medicine, pathogenesis, epidemiology, diagnosis, monitoring and treatment protocols. The journal is characterized by the rapid reporting of reviews, original research and clinical studies across all disease areas.

\section{Dovepress}

The manuscript management system is completely online and includes a very quick and fair peer-review system, which is all easy to use. Visit http://www.dovepress.com/testimonials.php to read real quotes from published authors. 